\title{
Targeting Synaptic Plasticity in Experimental Models of Alzheimer's Disease
}

\author{
Dalila Mango ${ }^{1+}$, Amira Saidi ${ }^{1+}$, Giusy Ylenia Cisale ${ }^{2}$, Marco Feligioni ${ }^{1,3}$, Massimo Corbo $^{3}$ \\ and Robert Nisticò ${ }^{1,4 *}$
}

${ }^{1}$ Laboratory of Neuropharmacology, EBRI Rita Levi-Montalcini Foundation, Rome, Italy, ${ }^{2}$ Department of Physiology and Pharmacology, Sapienza University of Rome, Italy, ${ }^{3}$ Department of Neurorehabilitation Sciences, Casa Cura Policlinico, Milan, Italy, ${ }^{4}$ School of Pharmacy, Department of Biology, University of Rome Tor Vergata, Rome, Italy

\section{OPEN ACCESS}

Edited by:

Cesare Mancuso,

Catholic University of

the Sacred Heart, Italy

Reviewed by:

Filippo Caraci,

University of Catania, Italy

Ai Na Ng,

University of Bristol, United Kingdom

${ }^{*}$ Correspondence:

Robert Nisticò

robert.nistico@uniroma2.it

tThese authors have contributed equally to this work.

Specialty section:

This article was submitted to Experimental Pharmacology and

Drug Discovery,

a section of the journa

Frontiers in Pharmacology

Received: 09 May 2019

Accepted: 17 June 2019

Published: 16 July 2019

Citation:

Mango D, Saidi A, Cisale GY,

Feligioni $M$, Corbo $M$ and Nisticò R (2019) Targeting Synaptic Plasticity in Experimental Models of Alzheimer's Disease.

Front. Pharmacol. 10:778. doi: 10.3389/fphar.2019.00778
Long-term potentiation (LTP) and long-term depression (LTD) of hippocampal synaptic transmission represent the principal experimental models underlying learning and memory. Alterations of synaptic plasticity are observed in several neurodegenerative disorders, including Alzheimer's disease (AD). Indeed, synaptic dysfunction is an early event in $\mathrm{AD}$, making it an attractive therapeutic target for pharmaceutical intervention. To date, intensive investigations have characterized hippocampal synaptic transmission, LTP, and LTD in in vitro and in murine models of AD. In this review, we describe the synaptic alterations across the main $A D$ models generated so far. We then examine the clinical perspective of LTP/LTD studies and discuss the limitations of non-clinical models and how to improve their predictive validity in the drug discovery process.

Keywords: long-term potentiation, long-term depression, synaptic plasticity, Alzheimer's disease, predictive validity

\section{INTRODUCTION}

Long-term synaptic plasticity is considered the neural basis of learning and memory process (Bliss and Collingridge, 1993). Long-term potentiation (LTP) and long-term depression (LTD) are the major forms of durable synaptic strength changes in central nervous system abundantly studied in the hippocampal region (Malenka and Bear, 2004). The magnitude of LTP and LTD is largely used in many different experimental conditions and animal models as an indicator of cognitive function; on the other hand, dysregulation of synaptic plasticity underlies a large number of neurodegenerative disorders such as Alzheimer's disease (AD) (Selkoe, 2002).

$\mathrm{AD}$ is a multifaceted neurodegenerative disorder typified by a progressive and irreversible memory deficits and cognitive decline. To date, AD can only be diagnosed post-mortem, through two characteristic neuropathological lesions in the brain: senile plaques, consisting of $\beta$-amyloid protein oligomers aggregates $(A \beta O$, residues $1-40 / 42)$, and intracellular neurofibrillary tangles (NFT), constituted of abnormally hyperphosphorylated tau protein accumulation predominantly

\footnotetext{
Abbreviations: $A \beta$, amyloid $\beta$ protein; $A \beta o, \beta$-amyloid protein oligomers aggregates; $A D$, Alzheimer's disease; AMPAR, L- $\alpha$ amino-3-hydroxy-5-methyl-4-isoxazole propionate receptor; APP, amyloid precursor protein; BST, basal synaptic transmission; E-LTP, early-LTP; FAD, familiar Alzheimer's disease; LFS, low frequency stimulation; LTD, long-term depression; LTP, long-term potentiation; L-LTP, late- LTP; mGlu, metabotropic glutamate receptor; NFT; neurofibrillary tangles; PPF, paired pulse facilitation; Tg, transgenic; WT PS1, wild-type human PS1; NA, not assessed; rTMS, repetitive transcranial magnetic stimulation; $\mathrm{SAD}$, sporadic Alzheimer's disease; tDCS, transcranial direct current stimulation.
} 
in hippocampal and cortical regions. The "amyloid cascade hypothesis" is so far the prominent theory to describe the timecourse of AD neurodegeneration (Hardy and Higgins, 1992). Impaired synaptic function of the hippocampus is an early event leading to defective hippocampal-dependent memory appearing long before the buildup of amyloid plaques and neuronal cell death (Selkoe, 2002; Tanzi, 2005). Therefore, synaptic plasticity is often used to evaluate part of the phenotype. Accordingly, many electrophysiological studies on the different models have been performed to delineate such changes.

Early impairments in synaptic transmission were highlighted in different mouse models of $\mathrm{AD}$ and are caused, among other factors, by A $\beta$ which leads to impairment of LTP via tau protein (Shipton et al., 2011). Notably, many studies investigated the correlation between age and synaptic dysfunction in order to describe the onset and development of pathology in a specific mouse model. Discrepancy in the results obtained by the different researchers across the various models of $\mathrm{AD}$ may reflect the type of mutation studied, in addition to several other sources of variations such as experimental design, age, or strain.

\section{LTP AND LTD IN NORMAL CONDITIONS}

Several studies indicate that the hippocampus plays a crucial role in higher cognitive functions and in information-storage (reviewed by Neves et al., 2008). LTP was first studied in the hippocampus and has been widely characterized using biochemical, electrophysiological, and molecular techniques (reviewed by Bliss et al., 2007). LTP is characterized by a shortterm phase (early- or E-LTP) and a subsequent long-term phase of potentiation (late- or L-LTP) (Reymann et al., 1989). Importantly, distinct forms of $\mathrm{N}$-methyl-D-aspartate (NMDA) receptor LTP coexist at synapses (Park et al., 2014) and these can also be distinguished based on their responsiveness to protein kinase $\mathrm{A}$ (PKA) inhibitors (Park et al., 2016). E-LTP and L-LTP can be induced in hippocampal slices by different induction protocols and are sustained by distinct cellular and molecular pathways. E-LTP $(<1 \mathrm{~h})$ is characterized by the recruitment of postsynaptic 2-amino-3-(3-hydroxy-5-methyl-isoxazol-4-yl)propionic acid (AMPA) receptors, either from neighboring extra synaptic receptors or from intracellular reserve pool by exocytosis (Penn et al., 2017). On the other hand, L-LTP (>3 h) involves de novo protein synthesis promoting structural and functional changes (Frey et al., 1988). Among the key players facilitating the transition from E-LTP to L-LTP, brain-derived neurotrophic factor (BDNF) (Panja and Bramham, 2014) and transforming growth factor $\beta 1$ (TGF- $\beta 1$ ) (Caraci et al., 2015; Caraci et al., 2018) are noteworthy.

The classical form of LTD can be experimentally elicited using specific electrical low-frequency stimulation (LFS) protocols in slices (Dudek and Friedlander, 1996). Most of the LTD forms studied imply activation of NMDA receptors (Dudek and Friedlander, 1996) and/or metabotropic glutamate (mGlu) receptors (Fitzjohn et al., 1999). Other chemical forms of LTD are obtained either by exogenous application of NMDA or muscarinic receptor agonists (reviewed by Collingridge et al., 2010), as well as through activation of microglia (Zhang et al., 2014).

\section{LTP AND LTD IN EXPERIMENTAL AD}

\section{In Vitro Models}

The peptide amyloid beta is released endogenously during physiologic neuronal activity and causes enhancement of synaptic plasticity and memory formation when administered at picomolar concentrations that likely resemble the physiological level in the brain (Puzzo et al., 2008; Morley et al., 2010; Puzzo et al., 2011; Lawrence et al., 2014). Conversely, a prolonged exposure to the same amount is able to impair synaptic plasticity by glutamate-induced excitotoxicity (Koppensteiner et al., 2016). Specifically, it has been demonstrated that NR2B-containing NMDA receptors and $m$ Glu5 receptors mediate the synaptotoxic effects of A $\beta$ o (Rammes et al., 2017).

The effects of acute application of exogenous $A \beta$ oligomers $(\mathrm{A} \beta \mathrm{o})$ obtained from synthetic, secreted from $\mathrm{AD}$ transgenic cells, or extracted from AD patients' brain, on synaptic transmission, have been widely studied in ex vivo hippocampal slices. All studies suggest that treatment of hippocampal slices with A $\beta$ o 200-500 $\mathrm{nM}$ induces alteration in LTP and LTD, generally manifested as loss of LTP and enhancement of LTD (Lambert et al., 1998; Wang et al., 2002; Shankar et al., 2008; Li et al., 2009; Jo et al., 2011; Cavallucci et al., 2013; Mango et al., 2016). Additionally, another study has shown that over-expression of $A \beta$ in organotypic slices reduces the number of surface L- $\alpha$-amino-3-hydroxy-5-methyl4-isoxazole propionate receptor (AMPAR) similar to what occurs in mGlu receptor-dependent LTD (Kamenetz et al., 2003). Recently, we have demostrated that hippocampal mouse slices treated with A $\beta$ o display an enhancement of $\mathrm{mGlu}$ receptordependent LTD (Mango and Nisticò, 2018).

\section{AD Mouse Models}

Animal models of AD should fully model human features of disease including gradual cognitive decline, synaptic dysregulation and spine loss, plaque load and NFT accumulation, inflammation, neurodegeneration, and atrophy of the central nervous sistem (CNS).

The breakthrough of amyloid precursor protein (APP) and PS human mutations has led to the generation of transgenic ( $\mathrm{Tg}$ ) animal models which strictly replicate the cardinal features of $\mathrm{AD}$. AD models are largely used to explore in a spatiotemporal manner the pathogenic mechanisms of $\mathrm{AD}$ and the benefit of therapeutic approaches.

Several lines of transgenic models of AD have been generated so far; each recapitulates specific aspects of the disease. They exemplify more integrated approaches to examine the complex effects of $A \beta O$ on brain integrity and network function. Several mouse models have been so far analyzed for hippocampal synaptic function by means of electrophysiological techniques (see Table 1). To simplify, we divide them in APP-derived, PS1derived, APP/PS1, 3xTg, and 5xTg models. Most of these models are constructed on the overexpression of familial AD (FAD)linked mutated genes into the mouse genome, and magnitude of LTP and LTD has been used to study synaptic plasticity alterations. Several exhaustive reviews on this topic have been published in the literature (Morrissette et al., 2009; Ashe and Zahs, 2010; Elder et al., 2010; Marchetti and Marie, 2011; Spires-Jones and Knafo, 2012; 
TABLE 1 | The table summarizes relevant data relative to experimental Alzheimer's disease (AD) models for which hippocampal electrophysiological analyses were performed.

\begin{tabular}{|c|c|c|c|c|c|c|c|c|}
\hline \multirow[t]{2}{*}{ Categories } & & \multirow[t]{2}{*}{ Models } & \multirow[t]{2}{*}{ Species } & \multicolumn{4}{|c|}{ Electrophysiological alteration } & \multirow[t]{2}{*}{ References } \\
\hline & & & & BST & PPF & LTP & LTD & \\
\hline \multirow[t]{4}{*}{ In vitro models } & & Soluble $A \beta$ oligomers treatment of & Rat & - & - & $\downarrow \mathrm{CA} 1$ & - & Lambert et al. (1998) \\
\hline & & hippocampal slices & Rat & $\mathrm{NC}$ & & $\downarrow D G$ & NC & Wang et al. (2002) \\
\hline & & & Mouse & $\mathrm{NC}$ & $\mathrm{NC}$ & $\downarrow \mathrm{CA} 1$ & $\uparrow \mathrm{CA} 1$ & Shankar et al. (2008) \\
\hline & & $\begin{array}{l}\text { APP over-expression in } \\
\text { organotypic slices }\end{array}$ & Rat & $\downarrow$ & $\mathrm{NC}$ & $\downarrow \mathrm{CA} 1$ & - & Kamenetz et al. (2003) \\
\hline \multirow[t]{19}{*}{$\begin{array}{l}\text { Transgenic } \\
\text { animal models }\end{array}$} & $\begin{array}{l}\text { APP-derived } \\
\text { models }\end{array}$ & APP (K670N/M671L) (APP23) & Mouse & $\downarrow$ & $\mathrm{NC}$ & NC & - & Roder et al. (2003) \\
\hline & & APP (K670N/M671L) (Tg2576) & Mouse & NC & $\mathrm{NC}$ & $\begin{array}{l}\downarrow \mathrm{CA} 1 \\
\downarrow \mathrm{DG}\end{array}$ & - & Chapman et al. (1999) \\
\hline & & & Mouse & $\mathrm{NC}$ & NC & NC & $\uparrow \mathrm{CA} 1$ & D'Amelio et al. (2011) \\
\hline & & APP (V717F) (APPind) & Mouse & $\downarrow$ & $\mathrm{NC}$ & NC & - & Hsia et al. (1999) \\
\hline & & APP (K670N/M671L)/APP & Mouse & NC & $\mathrm{NC}$ & $\downarrow \mathrm{CA} 1$ & NC & Nalbantoglu et al. (1997) \\
\hline & & (V717F)(J20) & Mouse & NC & $\downarrow$ & $\downarrow D G$ & - & Palop et al. (2007) \\
\hline & & $\begin{array}{l}\text { APP (K670N/M671L)/PS1 } \\
\text { (P264L) (Tg2576/PS1) }\end{array}$ & Mouse & NC & $\mathrm{NC}$ & $\downarrow \mathrm{CA} 1$ & $\uparrow \mathrm{CA} 1$ & Lanté et al. (2015) \\
\hline & $\begin{array}{l}\text { PS1-derived } \\
\text { models }\end{array}$ & PS1 (M146L) & Mouse & - & - & $\uparrow \mathrm{CA} 1$ & - & Barrow et al. (2000) \\
\hline & & PS1 (WT)/PS1 (A246E) & Mouse & NC & $\mathrm{NC}$ & $\uparrow \mathrm{CA} 1$ & - & Parent et al. (1999) \\
\hline & & PS1(A246E) & Mouse & - & $\mathrm{NC}$ & NC-CA1 & - & Schneider et al. (2001) \\
\hline & & PS1 (L286V) & Mouse & $\mathrm{NC}$ & $\mathrm{NC}$ & $\downarrow \mathrm{CA} 1$ & - & Auffret et al. (2009) \\
\hline & $\begin{array}{l}\text { APP/PS } \\
\text { models }\end{array}$ & $\begin{array}{l}\text { APP (K670N/M671L)/PS1 } \\
\text { (M146L) }\end{array}$ & Mouse & $\downarrow$ & $\mathrm{NC}$ & $\downarrow \mathrm{CA} 1$ & & Trinchese et al. (2004) \\
\hline & & $\begin{array}{l}\text { APP (KM670/671NL)/PS1 } \\
(\mathrm{L} 166 \mathrm{P})\end{array}$ & Mouse & $\mathrm{NC}$ & - & $\downarrow \mathrm{CA} 1$ & & Calella et al. (2010) \\
\hline & & $\begin{array}{l}\text { APP (K670N/M671L)/PS1 } \\
\text { (P264L)(Tg2576/PS1) }\end{array}$ & Mouse & $\mathrm{NC}$ & $\mathrm{NC}$ & $\downarrow \mathrm{CA} 1$ & $\uparrow \mathrm{CA} 1$ & Chang et al., (2006) \\
\hline & & $\begin{array}{l}\text { APP (K670N/M671L)/PS1 } \\
\text { (M146V) }\end{array}$ & Mouse & $\mathrm{NC}$ & - & $\downarrow \mathrm{CA} 1$ & $\downarrow \mathrm{CA} 1$ & Song et al. (2014) \\
\hline & & APP (K670N/M671L)/PS2 (N141I) & Mouse & $\mathrm{NC}$ & NC & $\downarrow \mathrm{CA} 1$ & - & Richards et al.(2003) \\
\hline & & & & $\uparrow$ & $\downarrow$ & $\downarrow D G$ & - & \\
\hline & $3 x \operatorname{Tg}$ model & $\begin{array}{l}\text { APP (K670N/M671L)/MAPT } \\
\text { (P301L)/PS1 (M146V) }\end{array}$ & Mouse & $\downarrow$ & $\mathrm{NC}$ & $\downarrow \mathrm{CA} 1$ & - & Oddo et al. (2003) \\
\hline & 5xFAD model & $\begin{array}{l}\text { APP (K670N/M671L) /APP } \\
\text { (I716V) /APP (V717I)/PS1 } \\
\text { (M146L; L286V) }\end{array}$ & Mouse & $\downarrow$ & $\mathrm{NC}$ & $\downarrow \mathrm{CA} 1$ & - & Kimura et al. (2009) \\
\hline
\end{tabular}

Models were grouped into in vitro models, APP-derived, PS1-derived, APP/PS1, 3xTg, and 5xTg models. Electrophysiological readouts include basal synaptic transmission (BST), paired pulse facilitation (PPF), long-term potentiation (LTP), and long-term depression (LTD). For each model, we also report the principal references to the electrophysiological studies.

Peineau et al., 2018 or visit the Alzheimer forum at http://www. alzforum.org/res/com/tra/default.asp).

\section{APP-Derived Models}

These mice models over-express the human APP, which is mutated in one or more sites. The single mutations introduced in the APP gene represent mutations associated with FAD, which are termed the Swedish (swe, K670N \& M671L, Mullan et al., 1992), the Indiana (ind, V717F, Murrell et al., 1991; Hsia et al., 1999), the London (Ld, V171I, Goate et al., 1991), and the Arctic (E693G, Nilsberth et al., 2001) mutations. Other mouse models show a double mutation, such as the Swe mutation together with either the Indiana or Arctic mutation. These models manifest progressive $A \beta$ accumulation and plaques similar to those found in humans. $A \beta$ plaques observed in $\mathrm{AD}$ Tg mice brain appear structurally comparable to those discovered in the human brain; they start as diffuse plaques consisting mainly of $\mathrm{A} \beta 42$ with a dense $A \beta 42$ core that contains $A \beta 40$ with many other non-A $\beta$ components, among which are ubiquitin and synuclein (Yang et al., 2000). Moreover, these mice models show hyperphosphorylated tau and hippocampal-dependent memory deficits similar to human AD pathology, but do not show NFTs, cholinergic deficits, or neuronal death (Morrissette et al., 2009).

APP23 mice (Sturchler-Pierrat et al., 1997) display normal LTP in the hippocampus and prefrontal cortex at all ages tested (Roder et al., 2003). Tg2576 and the hAPPJ20 mouse models present an age-dependent reduction in LTP in the CA1 area (Nalbantoglu et al., 1997; Chapman et al., 1999; Fitzjohn et al., 2001; Balducci et al., 2011; D'Amelio et al., 2011) and in the dentate gyrus (Palop et al., 2007).

LTD has not been largely explored in APP-derived mouse models; only few studies have reported LTD measurement (D’Amelio et al., 2011; Cavallucci et al., 2013; Lanté et al., 2015). Both groups performed field recordings in hippocampal slices from Tg2576 mice and have shown enhanced NMDA receptordependent LTD starting already from 3 to 4 months of age. 
In addition, a recent study described alteration of mGludependent LTD in 4-month-old Tg2576 mice, elicited by perfusion of the group I mGlu agonist DHPG (Mango and Nisticò, 2018).

\section{PS1-Derived Models}

These models over-express the human presenilin gene (PS1) encoding an FAD mutation. Being part of the secretase complex, this gene is involved in the APP proteolysis. Presenilin variants do not produce neuropathology, but potentiate plaque deposition in APP transgenic mice. Electrophysiological studies have been performed on M146L, A246E, and L286V mutants (Parent et al., 1999; Barrow et al., 2000; Schneider et al., 2001; Auffret et al., 2009). A mouse model was also generated harboring the PS1ÆE9 FAD mutation, which results in a functional and non-cleavable modification of PS1 (Zaman et al., 2000). One knock-in mouse was engineered in which mouse PS1 was exchanged by its mutant M146V (Sun et al., 2005). These presenilin FAD mutants consistently exhibit an age-dependent increase of A $\beta 42$ with minor effect on $A \beta 40$; however, they do show amyloid plaques, tau pathology, cholinergic alterations, or neurodegeneration and present only a mild cognitive deficit (Games et al., 2006). Most studies report that young adult (up to 6 months) transgenic mice over-expressing PS1M146L, PS1M146V, PS1A246E, PS1 $\triangle \mathrm{E} 9$, or PS1L286V display enhanced CA1-LTP elicited using different conditioning protocols (Schneider et al., 2001; Oddo et al., 2003; Dewachter et al., 2008; Auffret et al., 2009). So far, no study described LTD in these mouse models.

\section{APP/PS1 Models}

To accelerate the brain $\mathrm{A} \beta$ accumulation and plaque aggregation, researchers crossed APP- and PS1-derived animal models. Most electrophysiological studies focused on double transgenic models harboring the human APPswe transgene together with the PS transgene.

APP/PS1 double mutant mice develop rapid and extensive A $\beta$ plaque accumulation, tau pathology, and cognitive defects, even though they lack cholinergic deficits, neuronal loss, and NFTs (Morrissette et al., 2009).

Most studies report a reduction of LTP in APPswe/PS1M146L (Gong et al., 2004; Trinchese et al., 2004, Trinchese et al., 2008), APPswe/PS1P246L (Chang et al., 2006), APPswe/PS1L166P (Calella et al., 2010), and APPswe/PS2N141I (Richards et al., 2003) mice. Using a standard LFS protocol, Chang and coauthors (2006) report a linear decline in CA1-LTD expression between 9 and 20 months of age in the APPswe/PS1P246L model. Moreover, loss of LTD was described in the APPswe/PS1M146V mouse model (Song et al., 2014). Also, a recent study has shown mGlu receptor-LTD impairment in the APPswe/PSEN1/DE9 (Yang et al., 2016), whereas no alteration in the basal transmission was found in this model (Volianskis et al., 2010).

\section{3xTg Model}

The 3xTg model over-expressing human APPswe and tau MAPTP301L and encoding a knock-in of PS1M146V was generated for the first time by Oddo et al. (2003). These mice display both $\mathrm{A} \beta$ aggregates and NFT and show hippocampal-dependent memory decline during aging. Also, they show cholinergic alterations and neuronal loss in the cortex (Oddo et al., 2003;
Perez et al., 2010). This model is advantageous since it presents a significant intracellular $A \beta$ deposition before the occurrence of extracellular plaques, which become evident around 12 months of age, and notably, it develops NFTs comparable to humans.

Concerning the functional aspects, 6-month-old 3xTg mice display impairment of LTP (Oddo et al., 2003), which correlates with intracellular $A \beta$ well before plaque and tangle pathology. Recently, other triple transgenic mice have been generated harboring APP, PS2, and tau mutations (Rhein et al., 2009; Grueninger et al., 2010) but electrophysiological investigations have not been performed so far.

\section{5xFAD Model}

5xFAD mice (Tg6799 line) harbor three APP and PS2 (M146V and $\mathrm{L} 286 \mathrm{~V}$ ) mutations that are causally related to FAD (Oakley et al., 2006). They exemplify one of the most early-onset mouse models with robust amyloid pathology (Oakley et al., 2006; Ohno et al., 2006, Ohno et al., 2007). Indeed, 5xFAD mice start developing amyloid deposition already from 2 months of age and show early hippocampal dysfunction, as evidenced by reduced basal synaptic transmission and LTP (Kimura and Ohno, 2009; Crouzin et al., 2013). This mouse model exhibits a strong pathology: at 1.5 months of age mice already express intracellular $\mathrm{A} \beta 42$, which massively progresses at 2 months of age with extracellular $A \beta$ accumulation, senile plaques, and lack of specific neuronal populations. Cognitive impairment is reported at 4-6 months of age (Oakley et al., 2006). LTD has not yet been investigated in this mouse model.

\section{CLINICAL RELEVANCE OF LTP/LTD}

Many of the mechanisms underlying LTP and LTD in the rodent hippocampal slice preparation are shared also in hippocampal tissue from patients undergoing surgery for intractable temporal lobe epilepsy. Indeed, LTP is induced in the temporal lobe and in the dentate gyrus in humans using similar protocols of stimulation (Chen et al., 1996; Beck et al., 2000) and is modulated by the different pharmacological approaches just as in nonclinical models. These studies further support the notion that also the human brain manifests LTP- and LTD-like events even though linking synaptic plasticity to human learning and memory remains a challenge (Bliss and Cooke, 2011). It also should be kept in mind that the human tissue investigated in electrophysiological studies is found in a pathological state, deriving from patients with an epileptic focus in the temporal lobe.

Notably, LTP- and LTD-like events are nowadays exploited in humans for therapeutic purposes. These plastic changes can be induced through several noninvasive techniques such as repetitive transcranial magnetic stimulation (rTMS) and transcranial direct current stimulation (tDCS) and are used for the treatment of a variety of neurological and psychiatric conditions, such as epilepsy, drug addiction, depression, Parkinson disease, neuropathic pain, tinnitus, and stroke (Schulz et al., 2013).

We can therefore hypothesize that stimulation of neuroplasticity in the early stages of $\mathrm{AD}$, through pharmacological and noninvasive approaches, can attenuate disease progression. 
Even though numerous therapeutic interventions reverse synaptic alterations and improve behavior in the non-clinical AD models, so far, there has been no successful translation into disease-modifying compounds in humans (Nisticò et al., 2012).

\section{PREDICTIVE VALUE OF AD MODELS}

Considering the recent clinical trial failures in $\mathrm{AD}$, there has been considerable discussion as to whether results obtained from non-clinical models are predictive or simply misleading. There are numerous reasons why non-clinical studies may have failed to predict clinical trial outcome. One of the main issues it that $\mathrm{Tg}$ mice carry FAD mutations, accounting for only $5-10 \%$ of all $\mathrm{AD}$ cases, while the vast majority of $\mathrm{AD}$ cases are sporadic ( $\mathrm{AD}$ ). As a consequence, these models have a low face and predictive validity for the sporadic form of $\mathrm{AD}$. Moreover, transgenic models normally overexpress APP with consequent overproduction several APP fragments. Of note, a knock-in mice with a phenotype more similar to human was recently generated (Saito et al., 2014). Another limitation is that each mouse model develops only specific characteristics of $\mathrm{AD}$ (i.e. $\mathrm{A} \beta$ vs. tau pahology) and does not recapitulate the complexity of the human disease. It has also to be taken into account whether animal models display a similar spatiotemporal profile of disease progression when compared to $\mathrm{AD}$ patients. For example, cognitive deficits usually precede plaque load in mice, whereas the opposite occurs in patients. An important issue to be considered is that the majority of AD models lack neuronal cell death, while a substantial neurodegeneration is observed in the human AD brain.

It can be argued that the various non-clinical models typify specific disease-related targets and pathways, a potential advantage for testing candidate molecules on selected targets involved in $\mathrm{AD}$ pathogenesis. Indeed, this target-driven approach in non-clinical models has been translated over the years into numerous clinical studies (Nisticò et al., 2012).

In addition to intrinsic limitations of animal models, experimental bias is another crucial factor. For example, gender- and litter-dependent differences, variability in transgene expression, and the different genetic background among models and even between active treatment and placebo groups should all be considered in translation. Also, diversities in brain anatomy, neuronal physiology, metabolism, and disease susceptibility play a central role. Moreover, given the complex dynamics of drugtarget interactions, in vivo studies in non-clinical models should include a complete pharmacokinetics/pharmacodynamics profile in order to ensure that the dose range and timing are specific to the target (e.g. based on receptor occupancy and/or correlative biomarker data). On the other hand, the therapeutic window and the off-target effects that may lead to adverse effects should also be identified especially for behavioral experiments.

To improve clinical translation, non-clinical endpoints need to be accurately selected and should employ a combination of disease-relevant approaches such as integrated neurophysiological/behavioral paradigms. Electrophysiological techniques record neural activity from large neural populations down to single cells and are ideal to measure synaptic plasticity, as well as firing activity and neural oscillations. A limitation is that this approach does not address spatiotemporal information and is not suitable for noninvasively detecting activity from deep brain regions. In contrast, functional neuroimaging provides a noninvasive spatiotemporal readout of changes in brain function, making it an invaluable tool for most clinical studies. Unfortunately, the use functional imaging has been limited in non-clinical setting due to the restricted applicability to animal models and the relatively high cost.

\section{CONCLUSIONS}

We have previously hypothesized that alterations in normal synaptic function are not only a key feature but also a leading cause of disease (Nistico and Collingridge, 2012). In this respect, LTP and LTD can serve as synapse survival and death signals, respectively. Thus, conditions that promote LTD, i.e. following excessive A $\beta$ load in the early-onset forms of disease, can lead to loss of synapses. On the other hand, promoting LTP, which is known to inhibit LTD (Peineau et al., 2007), can represent a protective mechanism to preserve synaptic plasticity and brain connectivity.

It seems important to investigate the molecular mechanisms that influence plasticity in the human brain and to determine whether its vulnerability to aging and neurodegeneration can be modified by pharmacological intervention. Considering that $\mathrm{AD}$ is a complex disease affecting multiple signaling pathways, therapeutic strategies should not be directed to a single target rather to a combination of targets. To ensure a successful outcome, therapy should start at an early stage of disease. In addition, highly sensitive and specific biomarkers should identify susceptible individuals at the onset of disease (Hampel et al., 2014).

Generally, the predictive value of non-clinical models in the drug discovery process has been largely debated independently of the therapeutic area (McGonigle and Ruggeri, 2014; Mullane and Williams, 2019). Accordingly, several compounds showing robust efficacy in experimental models of $\mathrm{AD}$ have failed so far in clinical trials. Once a lead compound is selected, selection of nonclinical endpoints through integrated approaches should reflect the clinical endpoints in phase I studies. Correct design of nonclinical studies can be a long, complex, and expensive process that may slow down the course of drug development (Mohs and Greig, 2017); nonetheless, the probability of successful approval and hence time saving and return on investment is certainly increased.

\section{AUTHOR CONTRIBUTIONS}

$\mathrm{DM}$, AS and GC prepared the manuscript and reviewed the drafts, MF and MC reviewed the drafts, RN conceived the idea, prepared the manuscript and reviewed the drafts. All authors contributed to the writing and final approval of the manuscript.

\section{FUNDING}

This work was supported by Fondazione Turano. 


\section{REFERENCES}

Ashe, K. H., and Zahs, K. R. (2010). Probing the biology of Alzheimer's disease in mice. Neuron 66, 631-645. doi: 10.1016/j.neuron.2010.04.031

Auffret, A., Gautheron, V., Repici, M., Kraftsik, R., Mount, H. T., Mariani, J., et al. (2009). Age-dependent impairment of spine morphology and synaptic plasticity in hippocampal CA1 neurons of a presenilin 1 transgenic mouse model of Alzheimer' s disease. J. Neurosci. 29, 10144-10152. doi: 10.1523/ JNEUROSCI.1856-09.2009

Balducci, C., Mehdawy, B., Mare, L., Giuliani, A., Lorenzini, L., Sivilia, S., et al. (2011). The $\gamma$-secretase modulator CHF5074 restores memory and hippocampal synaptic plasticity in plaque-free Tg2576 mice. J. Alzheimers Dis. 24, 799-816. doi: 10.3233/JAD-2011-101839

Barrow, P. A., Empson, R. M., Gladwell, S. J., Anderson, C. M., Killick, R., Yu, X., et al. (2000). Functional phenotype in transgenic mice expressing mutant human presenilin- 1. Neurobiol. Dis. 7, 119-126. doi: 10.1006/nbdi.1999.0276

Beck, H., Goussakov, I. V., Lie, A., Helmstaedter, C., and Elger, C. E. (2000). Synaptic plasticity in the human dentate gyrus. J. Neurosci. 20, 7080-7086. doi: 10.1523/JNEUROSCI.20-18-07080.2000

Bliss, T. V., and Collingridge, G. L. (1993). A synaptic model of memory: longtermpotentiation in the hippocampus. Nature 3616, 31-39. doi: 10.1038/ $361031 \mathrm{a} 0$

Bliss, T. V., and Cooke, S. F. (2011). Long-term potentiation and long-term depression: a clinical perspective. Clinics (Sao Paulo) 1, 3-17. doi: 10.1590/ S1807-59322011001300002

Bliss, T. V., Collingridge, G. L., and Morris, R. G. M., (2007). The Hippocampus Book. Andersen P, Morris RGM, Amaral DG, Bliss TVP, O'Keefe J, editors. New York: Oxford Univ. Press, 343-474.

Calella, A. M., Farinelli, M., Nuvolone, M., Mirante, O., Moos, R., Falsig, J., et al. (2010). Prion protein and Aâ-related synaptic toxicity impairment. EMBO Mol. Med. 2, 306-314. doi: 10.1002/emmm.201000082

Caraci, F., Gulisano, W., Guida, C. A., Impellizzeri, A. A., Drago, F., Puzzo, D., et al. (2015). A key role for TGF- $\beta 1$ in hippocampal synaptic plasticity and memory. Sci. Rep. 5, 11252. doi: 10.1038/srep11252

Caraci, F., Spampinato, S. F., Morgese, M. G., Tascedda, F. 4., Salluzzo, M. G., Giambirtone, M. C., et al. (2018). Neurobiological links between depression and AD: the role of TGF- $\beta 1$ signaling as a new pharmacological target. Pharmacol. Res. 130, 374-384. doi: 10.1016/j.phrs.2018.02.007

Cavallucci, V., Berretta, N., Nobili, A., Nisticò, R., Mercuri, N. B., and D’Amelio, M. (2013). Calcineurin inhibition rescues early synaptic plasticity deficits in a mouse model of Alzheimer's disease. Neuromolecular Med. 15, 541-548. doi: 10.1007/s12017-013-8241-2

Chang, E. H., Savage, M. J., Flood, D. G., Thomas, J. M., Levy, R. B., Mahadomrongkul, V., et al. (2006). AMPA receptor downscaling at the onset of Alzheimer's disease pathology in double knockin mice. Proc. Natl. Acad. Sci. U.S.A. 103, 3410-3415. doi: 10.1073/pnas.0507313103

Chapman, P. F., White, G. L., Jones, M. W., Cooper-Blacketer, D., Marshall, V. J., Irizarry, M., et al. (1999). Impaired synaptic plasticity and learning in aged amyloid precursor protein transgenic mice. Nat. Neurosci. 2, 271-276. doi: $10.1038 / 6374$

Chen, W. R., Lee, S., Kato, K., Spencer, D. D., Shepherd, G. M., and Williamson, A. (1996). Long-term modifications of synaptic efficacy in the human inferior and middle temporal cortex. Proc. Natl. Acad. Sci. U.S.A. 93, 8011-8015. doi: 10.1073/pnas.93.15.8011

Collingridge, G. L., Peineau, S., Howland, J. G., and Wang, Y. T. (2010). Long-term depression in the CNS. Nat. Rev. Neurosci. 11, 459-473. doi: 10.1038/nrn2867

Crouzin, N., Baranger, K., Cavalier, M., Marchalant, Y., Cohen-Solal, C., Roman, F. S., et al. (2013). Area-Specific alterations of synaptic plasticity in the 5XFAD mouse model of Alzheimer's disease: dissociation between Somato sensory cortex and hippocampus. PLoS One 8, e74667. doi: 10.1371/journal. pone. 0074667

D’Amelio, M., Cavallucci, V., Middei, S., Marchetti, C., Pacioni, S., Ferri, A., et al. (2011). Caspase-3 triggers early synaptic dysfunction in a mouse model of Alzheimer's disease. Nat. Neurosci. 14, 69-76. doi: 10.1038/nn.2709

Dewachter, I., Ris, L., Croes, S., Borghgraef, P., Devijver, H., Voets, T., et al. (2008). Modulation of synaptic plasticity and Tau phosphorylation by wildtype and mutant presenilin 1. Neurobiol. Aging 29, 639-652. doi: 10.1016/j. neurobiolaging.2006.11.019
Dudek, S. M., and Friedlander, M. J. (1996). Developmental down-regulation of LTD in cortical layer IV and its independence of modulation by inhibition. Neuron 16, 1097-1106. doi: 10.1016/S0896-6273(00)80136-1

Elder, G. A., Gama Sosa, M. A., and De Gasperi, R. (2010). Transgenic mouse models of Alzheimer's disease. Mt. Sinai J. Med. 77, 69-81. doi: 10.1002/ msj.20159

Fitzjohn, S. M., Kingston, A. E., Lodge, D., and Collingridge, G. L. (1999). DHPGinduced LTD in area CA1 of juvenile rat hippocampus: characterisation and sensitivity to novel mGlu receptor antagonists. Neuropharmacology 38, 15771583. doi: 10.1016/S0028-3908(99)00123-9

Fitzjohn, S. M., Morton, R. A., Kuenzi, F., Rosahl, T. W., Shearman, M., Lewis, H., et al. (2001). Age-related impairment of synaptic transmission but normal longterm potentiation in transgenic mice that overexpress the human APP695SWE mutant form of amyloid precursor protein. J. Neurosci. 21, 4691-4698. doi: 10.1523/JNEUROSCI.21-13-04691.2001

Frey, U., Krug, M., Reymann, K. G., and Matthies, H. (1988). Anisomycin, an inhibitor of protein synthesis, blocks late phases of LTP phenomena in the hippocampal CA1 region in vitro. Brain Res. 452, 57-65. doi: 10.1016/00068993(88)90008-X

Games, D., Buttini, M., Kobayashi, D., Schenk, D., and Seubert, P. (2006). Mice as models: transgenic approaches and Alzheimer's disease. J. Alzheimers Dis., 9, 133-149. doi: 10.3233/JAD-2006-9S316

Goate, A., Chartier-Harlan, M. C., Mullan, M., Brown, J., Crowford, F., Fidani, L., et al. (1991). Segregation of a missense mutation in the amyloid precursor protein gene with familial Alzheimer's disease. Nature 349, 704-706. doi: $10.1038 / 349704 \mathrm{a} 0$

Gong, B., Vitolo, O. V., Trinchese, F., Liu, S., Shelanski, M., and Arancio, O. (2004). Persistent improvement in synaptic and cognitive functions in an Alzheimer mouse model after rolipram treatment. J. Clin. Invest. 114, 1624-1634. doi: $10.1172 /$ JCI22831

Grueninger, F., Bohrmann, B., Czech, C., Ballard, T. M., Frey, J. R., Weidensteiner, C., et al. (2010). Phosphorylation of Tau at $S 422$ is enhanced by Abeta in TauPS2APP triple transgenic mice. Neurobiol. Dis. 37, 294-306. doi: 10.1016/j. nbd.2009.09.004

Hampel, H., Lista, S., Teipel, S. J., Garaci, F., Nisticò, R., Blennow, K., et al. (2014). Perspective on future role of biological markers in clinical therapy trials of Alzheimer's disease: a long-range point of view beyond 2020. Biochem. Pharmacol. 88, 426-449. doi: 10.1016/j.bcp.2013.11.009

Hardy, J. A., and Higgins, G. A. (1992). Alzheimer's disease: the amyloid cascade hypothesis. Science 256, 184-185. doi: 10.1126/science.1566067

Hsia, A. Y., Masliah, E., McConlogue, L., Yu, G. Q., Tatsuno, G., Hu, K., et al. (1999). Plaque-independent disruption of neural circuits in Alzheimer's disease mouse models. Proc. Natl. Acad. Sci. U.S.A. 96, 3228-3233. doi: 10.1073/pnas.96.6.3228

Jo, J., Whitcomb, D. J., Olsen, K. M., Kerrigan, T. L., Lo, S. C., Bru-Mercier, G., et al. (2011). Abeta(1-42) inhibition of LTP is mediated by a signaling pathway involving caspase-3, Akt1 and GSK-3beta. Nat. Neurosci. 14, 545-547. doi: $10.1038 / \mathrm{nn} .2785$

Kamenetz, F., Tomita, T., Hsieh, H., Seabrook, G., Borchelt, D., Iwatsubo, T., et al. (2003). APP processing and synaptic function. Neuron 37, 925-937. doi: 10.1016/S0896-6273(03)00124-7

Kimura, R., and Ohno, M. (2009). Impairments in remote memory stabilization precede hippocampal synapticand cognitive failuresin 5XFAD Alzheimer mouse model. Neurobiol. Dis. 33, 229-235. doi: 10.1016/j.nbd.2008.10.006

Koppensteiner, P., Trinchese, F., Fà, M., Puzzo, D., Gulisano, W., Yan, S., et al. (2016). Time dependent reversal of synaptic plasticity induced by physiological concentrations of oligomeric $\mathrm{A} \beta 42$ : an early index of Alzheimer's disease. Sci. Rep. 1, 6-32553. doi: 10.1038/srep32553

Lambert, M. P., Barlow, A. K., Chromy, B. A., Edwards, C., Freed, R., Liosatos, M., et al. (1998). Diffusible, nonfibrillar ligands derived from Abeta1-42 are potent central nervous system neurotoxins. Proc. Natl. Acad. Sci. U.S.A. 95, 64486453. doi: $10.1073 /$ pnas. 95.11 .6448

Lanté, F., Chafai, M., Raymond, E. F., Pereira, A. R., Mouska, X., Kootar, S., et al. (2015). Subchronic glucocorticoid receptor inhibition rescues early episodic memory and synaptic plasticity deficits in a mouse model of Alzheimer's disease. Neuropsychopharmacology 40, 1772-1781. doi: 10.1038/npp.2015.25

Lawrence, J. L., Tong, M., Alfulaij, N., Sherrin, T., Contarino, M., White, M. M., et al. (2014). Regulation of presynaptic $\mathrm{Ca} 2+$, synaptic plasticity and contextual 
fear conditioning by a $\mathrm{N}$-terminal beta amyloid fragment. J. Neurosci. 34, 14210-14218. doi: 10.1523/JNEUROSCI.0326-14.2014

Li, S., Hong, S., Shepardson, N. E., Walsh, D. M., Shankar, G. M., and Selkoe, D. (2009). Soluble oligomers of amyloid Beta protein facilitate hippocampal longterm depression by disrupting neuronal glutamate uptake. Neuron 62, 788-801. doi: 10.1016/j.neuron.2009.05.012

Malenka, R. C., and Bear, M. F. (2004). LTP and LTD: an embarrassment of riches. Neuron 44, 5-21. doi: 10.1016/j.neuron.2004.09.012

Mango, D., and Nisticò, R. (2018). Role of ASICla in A $\beta$-induced synaptic alterations in the hippocampus. Pharmacol. Res. 131, 61-65. doi: 10.1016/j. phrs.2018.03.016

Mango, D., Weisz, F., and Nisticò, R. (2016). Ginkgolic acid protects against $\mathrm{A} \beta$-induced synaptic dysfunction in the hippocampus. Front. Pharmacol. 7, 401. doi: $10.3389 /$ fphar.2016.00401

Marchetti, C., and Marie, H. (2011). Hippocampal synaptic plasticity in Alzheimer's disease: what have we learned so far from transgenic models? Rev. Neurosci. 22, 373-402. doi: 10.1515/rns.2011.035

McGonigle, P., and Ruggeri, B. (2014). Animal models of human disease: challenges in enabling translation. Biochem. Pharmacol. 87, 162-171. doi: 10.1016/j.bcp.2013.08.006

Mohs, R. C., and Greig, N. H. (2017). Drug discovery and development: role of basic biological research. Alzheimers Dement. (N Y) 3, 651-657. doi: 10.1016/j. trci.2017.10.005

Morley, J. E., Farr, S. A., Banks, W. A., Johnson, S. N., Yamada, K. A., and Xu, L. (2010). A physiological role for amyloid-beta protein: enhancement of learning and memory. J. Alzheimers Dis. 19, 441-449. doi: 10.3233/JAD-2010-1230

Morrissette, D. A., Parachikova, A., Green, K. N., and LaFerla, F. M. (2009). Relevance of transgenic mouse models to human Alzheimer disease. J. Biol. Chem. 284, 6033-6037. doi: 10.1074/jbc.R800030200

Mullan, M., Crawford, F., Axelman, K., Houlden, H., Lilius, L., Winblad, B., et al. (1992). A pathogenic mutation for probable Alzheimer's disease in the APP gene at the N-terminus of beta-amyloid. Nat. Genet. 1, 345-347. doi: 10.1038/ ng0892-345

Mullane, K., and Williams, M. (2019). Preclinical Models of Alzheimer's disease: Relevance and Translational Validity. Curr. Protoc. Pharmacol. 84 (1), e57. doi: $10.1002 / \mathrm{cpph} .57$

Murrell, J., Farlow, M., Ghetti, B., and Benson, M. D. (1991). A mutation in the amyloid precursor protein associated with hereditary Alzheimer's disease. Science 254, 97-99. doi: 10.1126/science. 1925564

Nalbantoglu, J., Tirado-Santiago, G., Lahsaïn, A., Poirier, J., Goncalves, O., Verge, G., et al. (1997). Impaired learning and LTP in mice expressing the carboxy terminus of the Alzheimer amyloid precursor protein. Nature 387, 500-505. doi: 10.1038/387500a0

Neves, G., Cooke, S. F., and Bliss, T. V. (2008). Synaptic plasticity, memory and the hippocampus: a neural network approach to causality. Nat. Rev. Neurosci. 9, 65-75. doi: $10.1038 / \mathrm{nrn} 2303$

Nilsberth, C., Westlind-Danielsson, A., Eckman, C. B., Condron, M. M., Axelman, K., Forsell, C., et al. (2001). The 'Arctic' APP mutation (E693G) causes Alzheimer's disease by enhanced Abeta protofibril formation. Nat. Neurosci. 4, 887-893. doi: 10.1038/nn0901-887

Nisticò, R., and Collingridge, G. (2012). The synaptic basis of Alzheimer's disease. Eur. J. Neurodegener. Dis. 1, 21-33.

Nisticò, R., Pignatelli, M., Piccinin, S., Mercuri, N. B., and Collingridge, G. (2012). Targeting synaptic dysfunction in Alzheimer's disease therapy. Mol. Neurobiol. 46, 572-587. doi: 10.1007/s12035-012-8324-3

Oakley, H., Cole, S. L., Logan, S., Maus, E., Shao, P., Craft, J., et al. (2006). Intraneuronal beta-amyloid aggregates, neurodegeneration, and neuron loss in transgenic micewith five familial Alzheimer's disease mutations: potential factors in amyloid plaque formation. J. Neurosci. 26, 10129-10140. doi: 10.1523/JNEUROSCI.1202-06.2006

Oddo, S., Caccamo, A., Shepherd, J. D., Murphy, M. P., Golde, T. E., Kayed, R., et al. (2003). Triple-transgenic model of Alzheimer's disease with plaques and tangles: intracellular A $\beta$ and synaptic dysfunction. Neuron 39, 409-421. doi: 10.1016/S0896-6273(03)00434-3

Ohno, M., Chang, L., Tseng, W., Oakley, H., Citron, M., Klein, W. L., et al. (2006). Temporal memory deficits in Alzheimer's mouse models: rescue by genetic deletion of BACE1. Eur. J. Neurosci. 23, 251-260. doi: 10.1111/j.1460-9568. 2005.04551.x
Ohno, M., Cole, S. L., Yasvoina, M., Zhao, J., Citron, M., Berry, R., et al. (2007). BACE1 gene deletion prevents neuron loss and memory deficits in 5XFAD APP/PS1 transgenic mice. Neurobiol. Dis. 26, 134-145. doi: 10.1016/j. nbd.2006.12.008

Palop, J. J., Chin, J., Roberson, E. D., Wang, J., Thwin, M. T., Bien-Ly, N., et al. (2007). Aberrant excitatory neuronal activity and compensatory remodeling of inhibitory hippocampal circuits in mouse models of Alzheimer's disease. Neuron 55, 697-711. doi: 10.1016/j.neuron.2007.07.025

Panja, D., and Bramham, C. R. (2014). BDNF mechanisms in late LTP formation: a synthesis and breakdown. Neuropharmacology 76, 664-676. doi: 10.1016/j. neuropharm.2013.06.024

Parent, A., Linden, D. J., Sisodia, S. S., and Borchelt, D. R. (1999). Synaptic transmission and hippocampal long-term potentiation in transgenic mice expressing FAD-linked presenilin 1. Neurobiol. Dis. 6, 56-62. doi: 10.1006/ nbdi. 1998.0207

Park, P., Volianskis, A., Sanderson, T. M., Bortolotto, Z. A., Jane, D. E., Zhuo, M., et al. (2014). NMDA receptor-dependent long-term potentiation comprises a family of temporally overlapping forms of synaptic plasticity that are induced by different patterns of stimulation. Philos. Trans. R. Soc. Lond., B, Biol. Sci. 369, 20130131. doi: 10.1098/rstb.2013.0131

Park, P., Sanderson, T. M., Amici, M., Choi, S. L., Bortolotto, Z. A., Zhuo, M., et al. (2016). Calcium-permeable AMPA receptors mediate the induction of the protein kinase a-dependent component of long-term potentiation in the hippocampus. J. Neurosci. 36, 622-631. doi: 10.1523/JNEUROSCI.3625-15. 2016

Peineau, S., Rabiant, K., Pierrefiche, O., and Potier, B. (2018). Synaptic plasticity modulation by circulating peptides and metaplasticity: involvement in Alzheimer's disease. Pharmacol. Res. 130, 385-401. doi: 10.1016/j.phrs.2018. 01.018

Peineau, S., Taghibiglou, C., Bradley, C., Wong, T. P., Liu, L., Lu, J., et al. (2007). LTP inhibits LTD in the hippocampus via regulation of GSK3beta. Neuron 53, 703-17.

Penn, A. C., Zhang, C. L., Georges, F., Royer, L., Breillat, C., Hosy, E., et al. (2017). Hippocampal LTP and contextual learning require surfacediffusion of AMPA receptors. Nature 549, 384-388. doi: 10.1038/nature23658

Perez, S. E., He, B., Muhammad, N., Oh, K. J., Fahnestock, M., Ikonomovic, M., et al. (2010). Cholinotrophic basal forebrain system alterations in 3xTg-AD transgenic mice. Neurobiol. Dis. 41, 338-352. doi: 10.1016/j.nbd.2010. 10.002

Puzzo, D., Privitera, L., Fa', M., Staniszewski, A., Hashimoto, G., Aziz, F., et al. (2011). Endogenous amyloid-beta is necessary for hippocampal synaptic plasticity and memory. Ann. Neurol. 69, 819-830. doi: 10.1002/ana.22313

Puzzo, D., Privitera, L., Leznik, E., Fà, M., Staniszewski, A., Palmeri, A., et al. (2008). Picomolar amyloid-beta positively modulates synaptic plasticity and memory in hippocampus. J. Neurosci. 28, 14537-14545. doi: 10.1523/JNEUROSCI.269208.2008

Rammes, G., Mattusch, C., Wulff, M., Seeser, F., Kreuzer, M., Zhu, K., et al. (2017). Involvement of GluN2B subunit containing N-methyl-d-aspartate (NMDA) receptors in mediating the acute and chronic synaptotoxic effects of oligomeric amyloid-beta (Abeta) in murine models of Alzheimer's disease (AD). Neuropharmacology 123, 100-115. doi: 10.1016/j.neuropharm. 2017.02.003

Reymann, K. G., Matthies, H. K., Schulzeck, K., and Matthies, H. (1989). N-methyl$\mathrm{D}$-aspartate receptor activation is required for the induction of both early and late phases of long-term potentiation in rat hippocampal slices. Neurosci. Lett. 96, 96-101. doi: 10.1016/0304-3940(89)90249-8

Rhein, V., Song, X., Wiesner, A., Ittner, L. M., Baysang, G., Meier, F., et al. (2009). Amyloid-beta and tau synergistically impair the oxidative phosphorylation system in triple transgenic Alzheimer's disease mice. Proc. Natl. Acad. Sci. U.S.A. 24;106, 20057-20062. doi: 10.1073/pnas.0905529106

Richards, J. G., Higgins, G. A., Ouagazzal, A. M., Ozmen, L., Kew, J. N., Bohrmann, B., et al. (2003). PS2APP transgenic mice, coexpressing hPS2mut and hAPPswe, show age-related cognitive deficits associated with discrete brain amyloid deposition and inflammation. J. Neurosci. 23, 8989-9003. doi: 10.1523/JNEUROSCI.23-26-08989.2003

Roder, S., Danober, L., Pozza, M. F., Lingenhoehl, K., Wiederhold, K. H., and Olpe, H. R. (2003). Electrophysiological studies on the hippocampus and prefrontal cortex assessing the effects of amyloidosis in amyloid precursor 
protein 23 transgenic mice. Neuroscience 120, 705-720. doi: 10.1016/S03064522(03)00381-6

Saito, T., Matsuba, Y., Mihira, N., Takano, J., Nilsson, P., Itohara, S., et al. (2014). Single app knock-in mouse models of Alzheimer's disease. Nat. Neurosci. 17, 661-663. doi: 10.1038/nn.3697

Shipton, O. A., Leitz, J. R., Dworzak, J., Acton, C. E., Tunbridge, E. M., Denk, F., et al. (2011). Tau protein is required for amyloid \{beta\}-induced impairment of hippocampal long-term potentiation. J. Neurosci. 31, 1688-1692. doi: 10.1523/ JNEUROSCI.2610-10.2011

Schneider, I., Reverse, D., Dewachter, I., Ris, L., Caluwaerts, N., Kuiperi, C., et al. (2001). Mutant presenilins disturb neuronal calcium homeostasis in the brain of transgenic mice, decreasing the threshold for excitotoxicity and facilitating longterm potentiation. J. Biol. Chem. 276, 11539-11544. doi: 10.1074/jbc.M010977200

Schulz, R., Gerloff, C., and Hummel, F. C. (2013). Non- invasive brain stimulation in neurological diseases. Neuropharmacology 64, 579-587. doi: 10.1016/j. neuropharm.2012.05.016

Selkoe, D. J. (2002). Alzheimer's disease is a synaptic failure. Science 298, 789-791. doi: 10.1126/science.1074069

Shankar, G. M., Li, S., Mehta, T. H., Garcia-Munoz, A., Shepardson, N., Smith, I., et al. (2008). Soluble amyloid $\beta$-protein dimers isolated directly from alzheimer disease patients potently impair synaptic plasticity and memory. Nat. Med. 14, 837-842. doi: 10.1038/nm 1782

Song, S., Wang, X., Sava, V., Weeber, E. J., and Sanchez-Ramos, J. (2014). In vivo administration of granulocyte colony-stimulating factor restores long-term depression in hippocampal slices prepared from transgenic APP/PS1 mice. J. Neurosci. Res. 92, 975-980. doi: 10.1002/jnr.23378

Spires-Jones, T., and Knafo, S. (2012). Spines, plasticity, and cognition in Alzheimer's model mice. Neural Plast., 28, 319836. doi: 10.1155/2012/319836

Sturchler-Pierrat, C., Abramowski, D., Duke, M., Wiederhold, K. H., Mistl, C., Rothacher, S., et al. (1997). Two amyloid precursor protein transgenic mouse models with Alzheimer disease-like pathology. Proc. Natl. Acad. Sci. U.S.A. 94, 13287-13292. doi: 10.1073/pnas.94.24.13287

Sun, X., Beglopoulos, V., Mattson, M. P., and Shen, J. (2005). Hippocampal spatial memory impairments caused by the familial Alzheimer's disease-linked presenilin 1 M146V mutation. Neurodegener. Dis. 2, 6-15. doi: 10.1159/ 000086426

Tanzi, R. E. (2005). The synaptic Abeta hypothesis of Alzheimer disease. Nat. Neurosci. 8, 977-979. doi: 10.1038/nn0805-977

Trinchese, F., Liu, S., Battaglia, F., Walter, S., Mathews, P. M., and Arancio, O. (2004). Progressive age-related development of Alzheimer-like pathology in APP/PS1 mice. Ann. Neurol. 55, 801-814. doi: 10.1002/ana.20101
Trinchese, F., Fa', M., Liu, S., Zhang, H., Hidalgo, A., Schmidt, S. D., et al. (2008). Inhibition of calpains improves memory and synaptic transmission in a mouse model of Alzheimer disease. J. Clin. Invest. 118, 2796-2807. doi: 10.1172/ JCI34254

Volianskis, A., Kostner, R., Molgaard, M., Hass, S., and Jensen., M. S. (2010). Episodic memory deficits are not related to altered glutamatergic synaptic transmission and plasticity in the CA1 hippocampus of the APPswe/ PS1deltaE9-deleted transgenic mice model of ss-amyloidosis. Neurobiol. Aging 31, 1173-1187. doi: 10.1016/j.neurobiolaging.2008.08.005

Wang, H. W., Pasternak, J. F., Kuo, H., Ristic, H., Lambert, M. P., Chromy, B., et al. (2002). Soluble oligomers of beta amyloid (1-42) inhibit long-term potentiation but not long-term depression in rat dentate gyrus. Brain Res. 924, 133-140. doi: 10.1016/S0006-8993(01)03058-X

Yang, F., Uéda, K., Chen, P., Ashe, K. H., and Cole, G. M. (2000). Plaque-associated alpha-synuclein (NACP) pathology in aged transgenic mice expressing amyloid precursor protein. Brain Res. 853, 381-383. doi: 10.1016/S0006-8993 (99)02207-6

Yang, W., Zhou, X., Zimmermann, H. R., Cavener, D. R., Klann, E., and Ma, T. (2016). Repression of the eIF2 $\alpha$ kinase PERK alleviates mGluR-LTD impairments in a mouse model of Alzheimer's disease. Neurobiol. Aging 41, 19-24. doi: 10.1016/j. neurobiolaging.2016.02.005

Zaman, S. H., Parent, A., Laskey, A., Lee, M. K., Borchelt, D. R., Sisodia, S. S., et al. (2000). Enhanced synaptic potentiation in transgenic mice expressing presenilin 1 familial Alzheimer's disease mutation is normalized with a benzodiazepine. Neurobiol. Dis. 7, 54-63. doi: 10.1006/nbdi.1999.0271

Zhang, J., Malik, A., Choi, H. B., Ko, R. W., Dissing-Olesen, L., and MacVicar, B. A. (2014). Microglial CR3 activation triggers long-term synaptic depression in the hippocampus via NADPH oxidase. Neuron 82, 195-207. doi: 10.1016/j.neuron. 2014.01.043

Conflict of Interest Statement: The authors declare that the research was conducted in the absence of any commercial or financial relationships that could be construed as a potential conflict of interest.

Copyright (c) 2019 Mango, Saidi, Cisale, Feligioni, Corbo and Nistico. This is an open-access article distributed under the terms of the Creative Commons Attribution License (CC BY). The use, distribution or reproduction in other forums is permitted, provided the original author(s) and the copyright owner(s) are credited and that the original publication in this journal is cited, in accordance with accepted academic practice. No use, distribution or reproduction is permitted which does not comply with these terms. 